\title{
Hydrotreating of Egyptian Heavy Vacuum Gas Oil over Co-Mo/Carbon Nanotube Catalyst
}

\author{
W. Ahmed \#, Hoda S. Ahmed, H.S. El-Sheshtawy, Nadia A. \\ Mohamed" and Asmaa I. Zahran \\ Egyptian Petroleum Research Institute, Naser City and *Chem. \\ Dept., Faculty of Education \& Science, Ain-Shams University \\ for Girls, Cairo, Egypt.
}

\begin{abstract}
7 HE HYDROTREATING catalyst development is an essential factor to produce clean fuels. The catalytic performance of CoMoS/CNT on Hydrotreating of the Egyptian heavy vacuum gas oil was investigated. Firstly the CNT was functionalized with concentrated $\mathrm{HNO}_{3}$. The Mo and Co wt\% were loaded on CNT by impregnation methods. The catalyst was characterized by X-ray diffraction, Raman Spectroscopy, TEM, and BET. The hydrotreating experiments were conducted on autoclave reactor at various operating conditions of Temperature (325-375) ${ }^{\circ} \mathrm{C}$, pressure (20-60) bar, time (2-6) h and cat/oil ratio of $1: 75,33$ and 10 . The result indicated that the CoMoS/CNT was an efficient for the hydrotreating process. Also, the hydride-sulfurization (HDS) enhanced with increasing catalyst/oil ratio. Moreover, Results revealed that the optimum condition (temperature $350{ }^{\circ} \mathrm{C}$, Pressure 40 bar, catalyst/oil ratio of $1: 75$ for $2 \mathrm{hr}$, was chosen. Additionally, even at low catalyst ratio of 1:75 an acceptable HDS\% of 77.1 was achieved.
\end{abstract}

Keywords: Hydrotreatment, Heavy vacuum gas oil (HVGO), Carbon nanotubes and CoMo/CNT.

Due to economical and pollution control aspects, up 2010 the world legislations limited the sulfur content in fuels to $<15 \mathrm{ppm}^{(1-4)}$. In order to meet this challenge, Nemours efforts to develop the hydrotreatment process, responsible for $\mathrm{S}$ and $\mathrm{N}$ removal, were potentially developed. Commercially, the MoS promoted by Co or $\mathrm{Ni}$ and supported on $\gamma-\mathrm{Al}_{2} \mathrm{O}_{3}$ are the most active catalysts for hydrotreating process $^{(5-6)}$. The Co-Mo based catalyst is highly selective for HDS whereas NiMo based catalyst is more selective for hydrodenitrogenation (HDN) and hydrogenation. consequently, Ni-Mo based catalysts consumes higher hydrogen than Co-Mo based catalysts for the same extent of HDS with identical feed ${ }^{(7)}$. Despite the good thermal and textural properties and the high metal dispersion ability of $\gamma-\mathrm{Al}_{2} \mathrm{O}_{3}{ }^{(8)}$, it forms a strong metal-support interaction ${ }^{(9)}$. This interaction prohibits the complete metals sulfidation which decline the required active sites ${ }^{(10)}$.

\#Corresponding author e- mail:

Waelepri2@yahoo.com, Fax: + (202)22747433, Tel: + (202)22747847-2015 
Nevertheless, this drawback motivates the researchers to propose another supports to CoMo catalysts for various gas oils and model compounds ${ }^{(9,11-14)}$.

Carbon nanotube (CNT) provide not only the $\gamma-\mathrm{Al}_{2} \mathrm{O}_{3}$ advantages of high thermal, mechanical strength and high surface area but also other unique properties such as excellent electron transporting capability ${ }^{(15)}$. The CNT have interesting features make it a potential catalyst support for many reactions ${ }^{(16,17)}$.It has a high surface area with controlled pore volume and pore size which reduce the carbon deposition and provide enough surface for metal dispersion ${ }^{(18)}$.Unlike alumina, the CNT hydrophobic surface limited the metal support interaction which facilitates the metal sulfidation process. Additionally, the acid treatment of CNT creates $\mathrm{OH}^{-}$ or $\mathrm{COO}^{-}$functional groups that enhance the $\mathrm{Co}$ and Mo dispersion ${ }^{(19-20)}$.

Dong et al. ${ }^{(21)}$ reported a significant increase in active $\mathrm{MoO}_{2}$ species molar percentage in Co-Mo/CNT and so enhanced HDS activity. Shang et al. (22) reported a much higher selectivity of $\mathrm{Co}-\mathrm{Mo} / \mathrm{CNT}$ s catalyst than $\mathrm{Al}_{2} \mathrm{O}_{3}$-based catalyst. The author attributed the observation to the formation of $\mathrm{MoO}_{2}$ species rather than $\mathrm{MoO}_{3}$ formed over alumina support. Furthermore, it is also concluded that the highest catalytic performance can be achieved over the catalyst with 0.7 $\mathrm{Co} / \mathrm{Mo}$ atomic ratios.

Despite number of reports on Co-Mo/CNT for HDS were explored, there are no reports on the hydrotreating of Egyptian heavy vacuum gas oil (HVGO). Also there are rare researches in Co-Mo/CNT catalyst to feed ratio effect on the hydrotreating.

Therefore this study, concerns the Co-Mo/CNT catalytic performance toward the Egyptian HVGO hydrotreatment. In addition, the hydrotreating experimental conditions were optimized.

\section{Experimental}

\section{Feedstock}

Heavy vacuum gas oil (HVGO) kindly supplied by Suez Oil Petroleum Company (SOPC), has been used as the feedstock in the present investigation. The main characteristics of the feedstock are indicated in Table 1.

\section{Catalyst preparation}

Synthesis and purification of carbon nanotube

Carbon nanotube was kindly supplied by Awadallah research group (at Egyptian Petroleum Research Institute). They were prepared the CNT by CVD method according to Awadallah et al. ${ }^{(23)}$ The CNT were purified and functionalized by adding a conc. $\mathrm{HNO}_{3}$ and then stirred for $4 \mathrm{hr}$. Then it was filtered and washed by doubly distilled water several time, followed by drying at $120^{\circ} \mathrm{C}$ over night. 
TABLE 1. Properties of heavy vacuum gas oil feedstock.

\begin{tabular}{|l|c|c|}
\hline Experiment & Method & Result \\
\hline Density @ $15.56{ }^{\circ} \mathrm{C}, \mathrm{g} / \mathrm{ml}$ & ASTM D-1298 & 0.8867 \\
\hline Specific gravity & ASTM D-1298 & 0.8876 \\
\hline API gravity @ $60^{\circ} \mathrm{F}$ & ASTM D-1298 & 27.9 \\
\hline Total sulfur content, wt \% & ASTM D-4294 & 1.66 \\
\hline Aniline point & ASTM D-611-82 & 74 \\
\hline Diesel Index & ASTM D 611 & 46.09 \\
\hline Refractive Index @ 20 & ASTM-1218 & 1.4860 \\
\hline Kinematic viscosity, cSt, @ 40 ${ }^{\circ} \mathrm{C}$ & & 5.11 \\
\hline Pour point, ${ }^{\circ} \mathrm{C}$ & ASTM D-97 & +9 \\
\hline Flash point, ${ }^{\circ} \mathrm{C}$ & ASTM D-92 & 87 \\
\hline Color & & 2 \\
\hline Carbon, wt $\%$ & - & 86.66 \\
\hline Hydrogen, wt $\%$ & - & 11.69 \\
\hline Oxygen, wt $\%$ & - & 0.325 \\
\hline Component analysis & - & 63.875 \\
\hline Total saturates,wt. $\%$ & - & 34 \\
\hline Total aromatics, wt.\% & - & 2.125 \\
\hline Resin & - & \\
\hline
\end{tabular}

\section{Co-Mo loading}

In this study ammonium heptamolybdate tetrahydrate and cobalt acetate were used as the precursor for molybdenum and cobalt, respectively. The catalyst with $12 \mathrm{wt} \% \mathrm{MoO}_{3}$ loading and $\mathrm{Co} / \mathrm{Mo}$ atomic ratio of 0.7 were prepared by a pore volume impregnation method. The impregnation was carried out in two stages to avoid the precipitation of catalyst metal from the saturated solution. Firstly, the Mo loading, was carried out by dissolving the required weight of ammonium heptamolybdate tetrahydrate in a predetermined volume of doubly distilled water with a few drops of $\mathrm{H}_{2} \mathrm{O}_{2}$ to give a transparent solution. The solution was added to the needed CNT amount and stirred for $30 \mathrm{~min}$. After impregnation; the formed moist paste was preliminary dried in an oven at $120{ }^{\circ} \mathrm{C}$ over night. The dried samples were calcined in a muffle furnace with a heating rate of $10^{\circ} \mathrm{C} \mathrm{min}^{-1}$ up to $400{ }^{\circ} \mathrm{C}$ for $4 \mathrm{~h}$. Afterwards, the Co precursor introduced by pore volume impregnation, followed by drying at $120{ }^{\circ} \mathrm{C}$ over night. Finally the bimetallic catalysts were calcined at 400 in a muffle furnace for $4 \mathrm{hr}$.

\section{Catalyst Characterization \\ $X$-ray diffraction}

The X-ray diffraction for the prepared catalyst analysis was performed using X'Pert PRO PANalytical apparatus. The patterns were conducted using $\mathrm{Cu} \mathrm{K \alpha}$ radiation $(\lambda=0.1541 \mathrm{~nm})$. The $2 \theta$ ranges from $10^{\circ}$ to $70^{\circ}$ at a scanning rate of $0.05 \mathrm{~s}^{-1}$ were used to record the patterns. 
Transmission Electron Microscopy

The morphological properties for the CNT and Co-Mo/CNT catalysts were conducted using a JEOL 2010F TEM apparatus. The images were taken at an accelerating voltage of $200 \mathrm{kV}$. To prepare the samples, it diluted with $5 \mathrm{ml}$ ethanol to make a suspension. The mixture was sonicated for $20 \mathrm{~min}$ then a drop of solution was placed on a carbon coated $\mathrm{Cu}$ grid. Ethanol was then slowly evaporated from the $\mathrm{Cu}$ grid under a glass cover.

\section{Raman Spectroscopy}

Raman spectra of the as-grown carbon nanotube and Co-Mo/CNT samples were recorded by SENTERRA Dispersive Raman Microscope (Bruker). The apparatus was equipped with a diode $\mathrm{Nd}$ : YAG laser and wave length of $532 \mathrm{~nm}$. The experiments were carried out at room temperature in range of 10 to $2000 \mathrm{~cm}^{-1}$.

\section{Surface area measurement}

The phesico-chemical properties of the prepared catalyst were determined by $\mathrm{N}_{2}$ adsorption-desorption method at $-196{ }^{\circ} \mathrm{C}$. The BET surface area was measured by using Autosorb 1, Quanta chrome instrument. Prior to the measurement, the catalyst was degassed at $200{ }^{\circ} \mathrm{C}$ for $4 \mathrm{hr}$ to remove the adsorbed gases and moisture. Surface area was calculated using the adsorption data up to a relative pressure of 0.1 by BET method.

\section{Catalytic activity test}

Prior to the activity tests (i.e. hydrotreating), the catalyst is presulfied in-situ (in the autoclave) at the following conditions: 15 bar, initial hydrogen pressure, $350{ }^{\circ} \mathrm{C}$ reaction temperature and $5 \mathrm{hr}$ reaction period. A mixture of light gas oil contains $8 \%$ (of the catalyst weight) dimethyldisulfide (DMDS) was used as sulfiding agent.

The hydrotreating run experiments were carried out in a static phase using batch reactor (parr.model 7575). After sulfiding experiment, the temperature of the autoclave is lowered to room temperature, then the sulfided catalyst is transferred out and kept in a vacuum environment, so that contact with air is avoided, till used. The hydrotreating run experiments were carried out in a static phase using batch reactor. The reactor is housed in a furnace; there is programmed control system for controlling temperature and speed of the stirrer. Pressure and flow of gases are controlled manually. Amount of $150 \mathrm{~g}$ feed and $2 \mathrm{~g}$ of the investigated sulfided catalyst are loaded inside the reactor. After tightly closing the reactor, reactant and catalyst was purged in $\mathrm{N}_{2}$ in order to check the pressure leakage. The hydrotreatment operation conditions of temperature (325$375)$, initial pressure (20-60 bar), time (2-6 hr) and catalyst to feed ratio of $1: 75$, 33 and 10 were investigated.

After the required temperature, pressure over a constant catalyst/oil ratio has reached; the experiment was conducted for the desired time. Afterwards, the 
autoclave was maintained to cool to room temperature overnight and the total pressure decreased. The liquid products were collected out of the autoclave and then the catalyst was filtered and washed by solvent (naphtha). The filtered catalyst was heated in an electric oven at $110{ }^{\circ} \mathrm{C}$ for $2 \mathrm{hr}$. Liquid product is purged out the reactor under sufficient $\mathrm{N}_{2}$-pressure, and collected for analysis using the recommended standard methods (i.e. ASTM or IP methods).

\section{$X$-ray diffraction}

\section{Result and Discussion}

Figure 1 demonstrated the XRD patterns of the acid treated CNT and supported catalyst after calcinations. Figure 1.a. indicated that the functionalized CNT support had peaks at about $2 \theta$ of $26.05^{\circ}$ and $43.08^{\circ}$ which ascribed to the (002) graphitic basal plane and the diffraction of (100) plane, respectively ${ }^{(22,24,25)}$. This observation indicated the low graphitization degree of CNT used in this study. Neither peaks for $\mathrm{Mg}$ nor $\mathrm{Ni}$ were assigned in the pure CNT diffractogram. This result revealed that the appropriate nitric acid treatment of CNT led to removal of all $\mathrm{Ni}$ and $\mathrm{Mg}$ ions. Additionally, the results might generally have been responsible for catalysts high surface area ${ }^{(26)}$. The XRD patterns of Co-Mo loaded CNT and S-Mo/CNT was illustrated in Fig. 1b and 1c, respectively. The main CNT peaks intensities were decreased by metals loading. Tan et al. ${ }^{(27)}$ reported that this decrease in CNT patterns may attributed to a change in ordered structure because of metals loading.

Mo loaded CNT sample (Fig. 1 b) showed the diffraction peaks at $2 \theta$ of $26.18^{\circ}, 36.98^{\circ}, 53.58^{\circ}$ and $60.58^{\circ}$ which characteristics for $\mathrm{MoO}_{2}{ }^{(22,28)}$. Furthermore, very low intensity peaks for $\mathrm{MoO}_{3}$ crystalline phase were measured. The presence of $\mathrm{MoO}_{3}$ weak peaks might be attributed to slightly incomplete acidification of some CNT surface and hence lower functional groups ${ }^{(9)}$. These results concluded that the majority of Mo species present under reaction conditions on the surface of the CNT were those at low valence values. This may explained by the CNTs surface hydrophobicty which weakening the metal-support interaction ${ }^{(29)}$. The lower metal-support interaction allows the $\mathrm{MoO}_{3}$ to migrate and conglomerate on the CNTs surface. Meanwhile, the Mo species reduced into the lower valence state during the calcination. Previous studies were also reported the same observation ${ }^{(22,25,30)}$.

It is rather well known for HDS catalyst that, Mo oxide form must be sulfided to the active $\mathrm{MoS}_{2}$ at which the Mo becomes the $\mathrm{Mo}^{4+}$. Literature stated that the $\mathrm{MoO}_{3}$ supported alumina catalyst was easily sulfided to the active $\mathrm{MoS}_{2}$ rather than $\mathrm{MoO}_{2} / \mathrm{Al}_{2} \mathrm{O}_{3}$. Meanwhile, the ease of either CNT-supported $\mathrm{MoO}_{3}$ or $\mathrm{MoO}_{2}$ sulfidation of is still a dark area.

Figure 1.c. showed the XRD patterns of $\mathrm{Co}-\mathrm{Mo} / \mathrm{CNT}$ after sulfiding. The figure demonstrated that neither $\mathrm{Co}_{3} \mathrm{O}_{4}$ nor its sulfide phases were detected. 
Weak broad peaks at $14.4^{\circ}$ and $32.71^{\circ}$ which attributed to $\mathrm{Mo}_{3} \mathrm{~S}_{4}$ crystallite formation were assigned. Moreover, a small peak at $29.0^{\circ}$ was observed. This peak may be due to the low valence $\mathrm{Co}-\mathrm{MoS}_{3.13}$ or $\mathrm{Co}-\mathrm{MoS}_{2.17}$ species formation ${ }^{(22)}$. Also, the peaks for molybdenum oxide species intensity were lowered. This might be explained by the replacement of the Co atoms on the $\mathrm{MoO}_{3}$ crystals and limiting their growth. Furthermore, no peaks related to the CNT, Co and Mo interactions were recorded. It maybe concluded that the cobalt loading and the sulfiding process emphasizes the active phase's dispersion on the CNT.

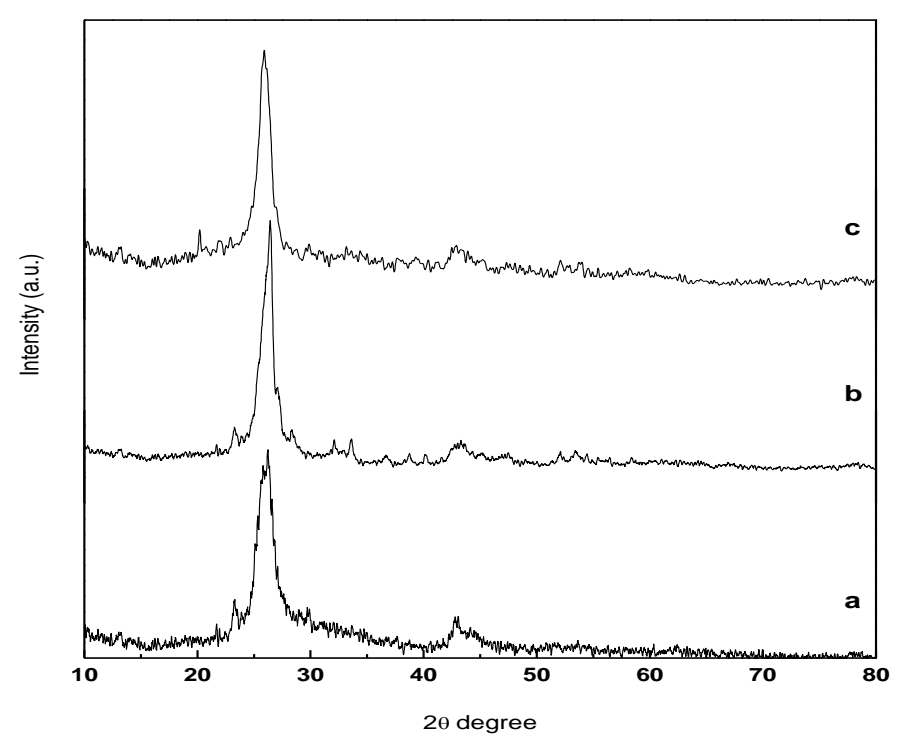

Fig. 1. XRD pattern of different samples (a) CNT, (b) CoMoO /CNT; (c) CoMoS /CNT.

Transmission Electron Microscopy (TEM)

The micrograph of the pure CNT and S-CoMo/CNT catalyst were shown in Fig. 2. The TEM image (Fig. 2.a.) showed the CNT morphological characteristics with uniform diameter. The TEM images revealed that the nanotubes had the average outer diameters of around $20 \mathrm{~nm}$. The nanotubes had wall thickness of about $10 \mathrm{~nm}$. The TEM images of the S-Co-Mo/CNT catalyst were shown in Fig. 2 b. The images demonstrated good metals dispersed over CNT support. This observation confirmed the data obtained from XRD. Additionally, no noticeable agglomeration of active phase was demonstrated. Furthermore, no Co metals inside the CNTs were detected. These results maybe explained via CNT inner diameter and its functional groups. Comparing Fig. 2a and $2 \mathrm{~b}$, it's clear that the CNT functional groups provide anchoring sites that prevent the cobalt particles immigration into the tubes and the particles sintering by calcination. Moreover, the narrow inner CNT channels diameter $(9-10 \mathrm{~nm})$

Egypt. J. Chem. 59, No. 3 (2016) 
hinders the small cobalt crystallites growth inside the tube ${ }^{(31)}$. It is reported that the TEM images of the CNT supported catalyst showed the smaller cobalt crystallites are lying inside the CNT channels and the larger ones are on the outside ${ }^{(32-34)}$. The EDX analysis (image entire in Fig. 2b) confirms the Co and Mo loadings with good intense peaks for both.

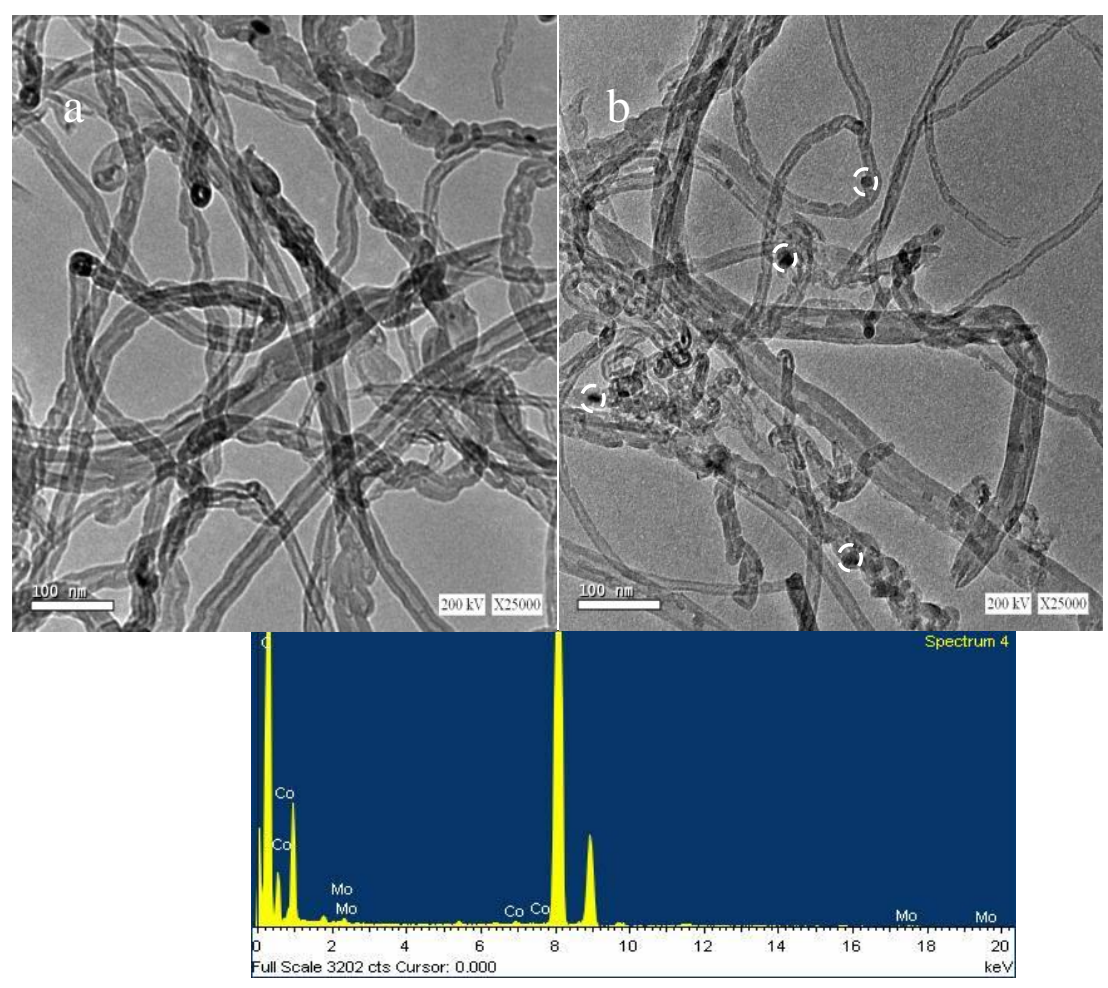

Fig. 2. TEM images of (a) CNT (b) CoMoS/CNT and EDX of CoMoO/CNT.

\section{Textural characteristics of CoMo/MWCNT}

The physical adsorption-desorption isotherms of $\mathrm{N}_{2}$ at $-196{ }^{\circ} \mathrm{C}$ for pure $\mathrm{CNT}$ and CoMoS/CNT catalysts were shown in Figure 3I. The isotherm corresponding to type IV was obtained for the pure CNT indicating the presence of mesopores. Figure 3 II showed the pore size distribution (PSD) calculated by the BJH method. The pretreated CNT and CoMoS/CNT PSD had the average of about 12 and $18 \mathrm{~nm}$, respectively. The specific surface area and pore volume data of CNT and CoMoS/CNT were listed in Table 2. It maybe concluded that, the BET surface area and pore volume were increased significantly after the nitric acid pretreatment. After metal impregnation, a consistent decrease in the $S_{\mathrm{BET}}$ and average pore diameter were observed. The decline of the surface area and pore size may due to the blocking of some microspores and surface smoothing by the 
metal deposition on the support. Thus, metal loading has a great effect in decreasing textural characteristics of catalyst.

TABLE 2. Physical properties of supports and CoMoX/support catalysts.

\begin{tabular}{|c|c|c|c|}
\hline Sample & $\begin{array}{c}\text { BET surface area } \\
\left(\mathbf{m}^{\mathbf{2}} \mathbf{g}\right)\end{array}$ & $\begin{array}{c}\text { Total pore volume } \\
\left(\mathbf{c m}^{\mathbf{3}} / \mathbf{g}\right)\end{array}$ & $\begin{array}{c}\text { Average pore } \\
\text { diameter }(\mathbf{n m})\end{array}$ \\
\hline $\mathrm{CNT}$ & 120.9 & 0.25 & 38.02 \\
\hline $\mathrm{CoMoO} / \mathrm{CNT}$ & 101.1 & 0.18 & 35.28 \\
\hline $\mathrm{CoMoS} / \mathrm{CNT}$ & 73.58 & 0.12 & 32.57 \\
\hline
\end{tabular}
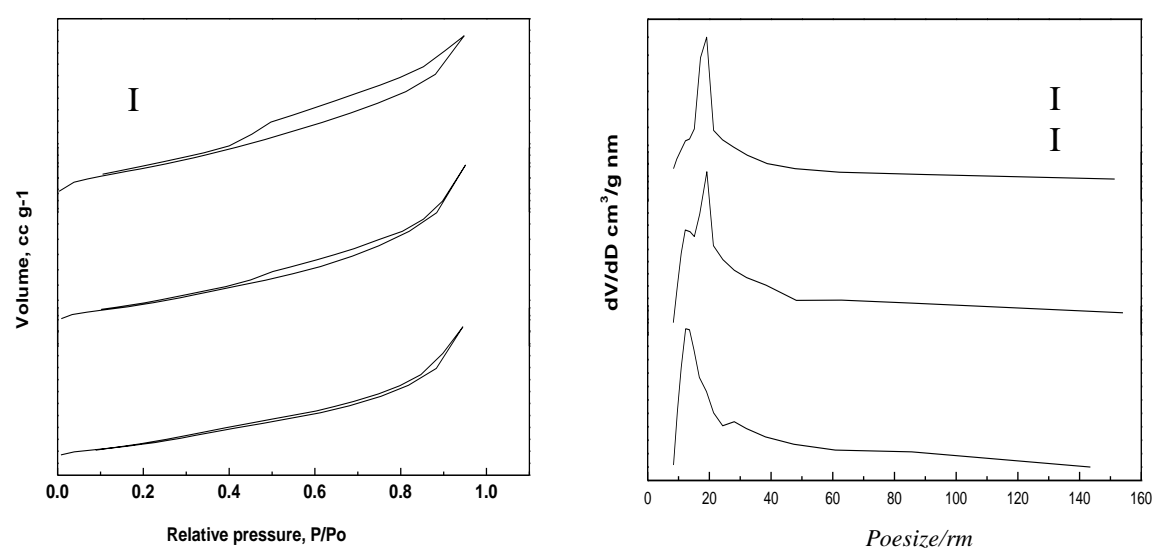

Fig. 3. $\mathrm{N}_{2}$ adsorption/desorption isotherm (I) and particle size distribution (II) exhibited for pure (a) CNT, (b) CoMoO/CNT and (c) CoMoS/CNT catalysts.

Raman spectroscopy

Figure 4 presents the Raman spectra for the supplied CNT, $\mathrm{CoMoO}_{4} / \mathrm{CNT}$ and sulfided catalyst. The pure CNT spectrum (Fig. 4 a) was displayed two prime intense peaks at about 1343 and $1575 \mathrm{~cm}^{-1}$. The peak at $1343 \mathrm{~cm}^{-1}$, which known as the D-band, was attributed to the disordered carbon ${ }^{(35)}$. The second peak, referred as $\mathrm{G}$ band, can interpret to the highly graphitized CNT. It is known that the $\mathrm{D}$ to $\mathrm{G}$ band relative intensity indicating the quality and purity of the produced CNTs. the lower intensity ratio of ID/IG proved the higher crystallinty and purity of the CNTs ${ }^{(36)}$. The spectra of the pure CNT acquire the low ID/IG ratio of 0.22 which reflect the very high CNTs crystallinty. Clearly, these results are in a good agreement with the XRD and TEM results (Fig. 1, 2).

Egypt. J. Chem. 59, No. 3 (2016) 
Raman spectra of the CoMoO4/CNT (Fig. 4 b.) showed only the peaks of the pure CNT. This result may be attributed to the good dispersion of the loaded metal oxides onto the carbon nanotubes. The Raman spectrum of the sulfided CoMo/CNT catalyst was showed in Fig. 4 c. The catalyst exhibited a band at $335 \mathrm{~cm}^{-1}$ and a large sharp peak at $940 \mathrm{~cm}^{-1}$ that can be assigned to the symmetric $\mathrm{Mo}=\mathrm{O}$ stretching of tetrahedral $\mathrm{MoO} 4{ }^{2-(22)}$. This result proved the higher dispersion of Mo during through preparation method. Moreover, our results indicted none of these known peaks for polymeric molybdates, bulk $\mathrm{CoMoO}_{4}$ or bulk Co or Mo were recorded. The literature stated that the bands at about 320 and $920 \mathrm{~cm}^{-1}$ are assigned for the monomeric Mo species while bands at about 220,360, and $960 \mathrm{~cm}^{-1}$ ascribed to the well-dispersed octamolybdates (37). Additionally, the bands at ca. 820,945 , and $952 \mathrm{~cm}^{-1}$ are attributed to the bulk $\mathrm{CoMoO}_{4}$. While, the characteristic bands of bulk Co and Mo oxides were normally assigned at $696 \mathrm{~cm}^{-1}$ and $820 \mathrm{~cm}^{-1}$, respectively ${ }^{(22,38)}$.

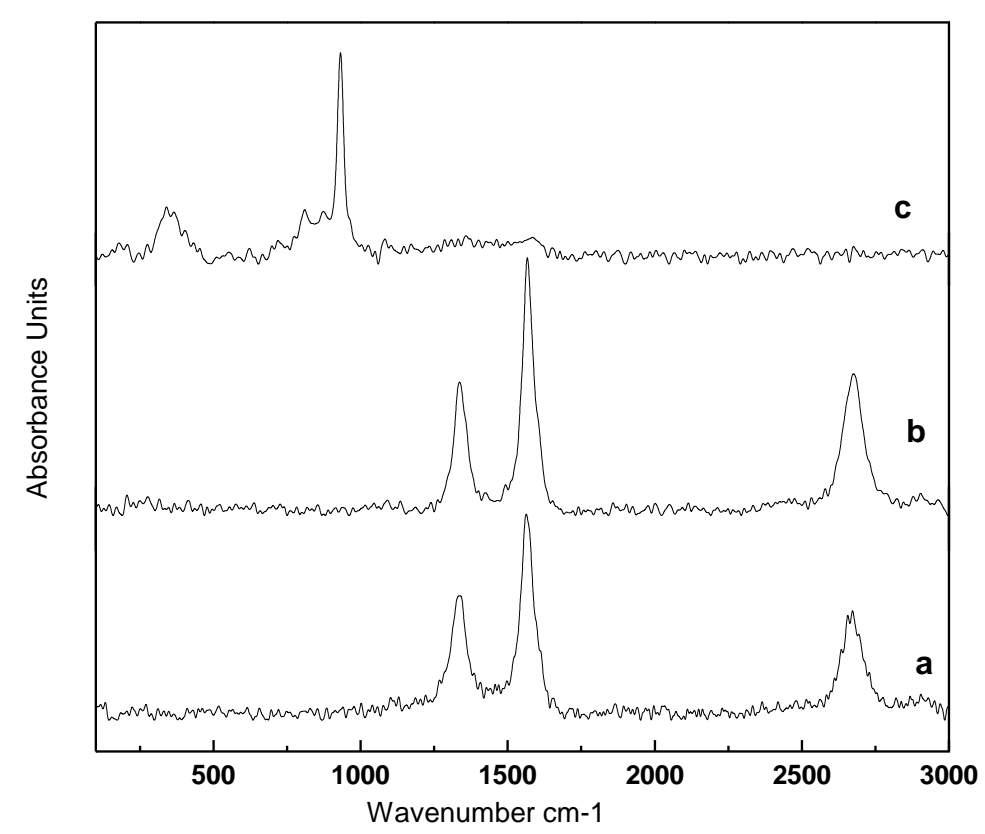

Fig. 4. Laser Raman spectra of (a) CNT, (b) CoMoO /CNT (c) CoMoS/CNT.

\section{Catalytic activity}

Effect of reaction temperature

Table 3 represented the effect of reaction temperature on the product quality. It was shown that yield of heavy vacuum gas oil (HVGO) was clearly affected by the reaction temperature (i.e.) decreased as the activity of the sulfided $\mathrm{CoO}$ $\mathrm{MoO}_{3} /$ carbon nanotube catalyst was increased due to the increasing in reaction severity. As a result the hydrodesulfrization (HDS) activity of the catalyst was 
increased continuously from (61.4 to $79.26 \%)$ at $325^{\circ} \mathrm{C}$ and $375{ }^{\circ} \mathrm{C}$, respectively at constant pressure (40 bar), constant time $(2 \mathrm{hr})$. The effects of temperature on aniline point, diesel index (DI) are given in Table 3 . These properties give an indication on the hydrogenation activity of the CoMoS/CNT catalyst. As the reaction temperature increased the aromatic content was decreased from (25 to $17.6 \%$ ) at $325{ }^{\circ} \mathrm{C}$ and $375{ }^{\circ} \mathrm{C}$, respectively. At the same time, the total saturates content, increased from 75 to $82.4 \%$ as the reaction temperature was increased from 325 to $375^{\circ} \mathrm{C}$, This is due to the hydrogenation of aromatics which is an exothermic reaction and was favored at low reaction temperature ${ }^{(39)}$.

TABLE 3. Effect of reaction temperature on Hydrotreating of HVGO by CoMoS/CNT at $P=40$ bar $\quad T=2 h \quad C / F=1: 75$.

\begin{tabular}{|l|c|c|c|c|}
\hline \multirow{2}{*}{ Characteristics } & \multicolumn{4}{|c|}{ Temperature, ${ }^{\circ} \mathbf{C}$} \\
\cline { 2 - 5 } & Feed & $\mathbf{3 2 5}$ & $\mathbf{3 5 0}$ & $\mathbf{3 7 5}$ \\
\hline Total liquid yield, wt \% & 150 & 83.66 & 78 & 54 \\
\hline Total sulfur content, wt \% & 1.66 & 0.64 & 0.38 & 0.34 \\
\hline Sulfur reduction (HDS), \% & - & 61.4 & 77.1 & 79.26 \\
\hline Aniline point @ ${ }^{\circ} \mathrm{F}$ & 165.2 & 170.24 & 170.6 & 171.32 \\
\hline DI & 46.09 & 57.37 & 59.65 & 60.56 \\
\hline Density @ 15.56 ${ }^{\circ} \mathrm{C}, \mathrm{g} / \mathrm{ml}$ & 0.8867 & 0.8557 & 0.8492 & 0.8486 \\
\hline Specific gravity & 0.8876 & 0.8565 & 0.8500 & 0.8494 \\
\hline API gravity @ 60 ${ }^{\circ} \mathrm{F}$ & 27.9 & 33.70 & 34.97 & 35.35 \\
\hline RI @ 20 & 1.4860 & 1.4775 & 1.4730 & 1.4695 \\
\hline $\begin{array}{l}\text { Kinematic viscosity, cSt, @ } \\
\text { 40 }{ }^{\circ} \mathrm{C}\end{array}$ & 5.11 & 4.38 & 3.27 & 2.72 \\
\hline Pour point, ${ }^{\circ} \mathrm{C}$ & +9 & 3 & 3 & 0 \\
\hline Flash point, ${ }^{\circ} \mathrm{C}$ & 87 & 76 & 58 & 54 \\
\hline Color & 8 & 1 & 1 & 1 \\
\hline Component analysis & 63.88 & 75 & 78.5 & 82.4 \\
\hline Total saturates, wt.\% & 34 & 25 & 21.5 & 17.6 \\
\hline Total aromatics, wt.\% & - & 26.47 & 36.76 & 48.23 \\
\hline Resin & Hydrodearomatization (HDA), \\
wt\% & & & - & - \\
\hline
\end{tabular}

Egypt. J. Chem. 59, No. 3 (2016) 
Effect of hydrogen pressure

Results pricked on Table 4 show the following facts. As the total hydrogen pressure is increased from 20 to 60 bar, the effect on yield and quality characteristics of heavy vacuum gas oil were observed, (i.e.) HDS increased from $(60.24$ to $79.5 \%)$, DI and aniline point increased from (56.59 to $61.18 \%$ ) and (169.7 to172.4\%) respectively, while total aromatics content decreased from $24 \%$ at 20 bar to $16.8 \%$ at 60 bar, which can be attributed to the increase of hydrogenation activity of the catalyst with increasing total hydrogen pressure besides the increase of saturation activity and reduction of coke formation $^{(39,40)}$.

TABLE 4. Effect of reaction pressure on Hydrotreating of HVGO by CoMoS/CNT at $T=: 350{ }^{\circ} \mathrm{C} \quad \mathrm{T}=\mathbf{2 h} \quad \mathrm{C} / \mathrm{F}=\mathbf{1} \mathbf{1 : 7 5}$.

\begin{tabular}{|c|c|c|c|c|}
\hline \multirow{2}{*}{ Characteristics } & \multicolumn{4}{|c|}{ Pressure, bar } \\
\hline & Feed & 20 & 40 & 60 \\
\hline Total liquid yield, wt $\%$ & 150 & 85.33 & 78 & 72 \\
\hline Total sulfur content, wt $\%$ & 1.66 & 0.66 & 0.38 & 0.34 \\
\hline Sulfur reduction (HDS), \% & - & 60.24 & 77.1 & 79.5 \\
\hline Aniline point $@{ }^{\circ} \mathrm{F}$ & 165.2 & 169.7 & 170.6 & 172.4 \\
\hline DI & 46.09 & 56.59 & 59.65 & 61.18 \\
\hline Density@15.56 $\mathrm{C}, \mathrm{g} / \mathrm{ml}$ & 0.8867 & 0.8562 & 0.8492 & 0.8486 \\
\hline Specific gravity & 0.8876 & 0.8570 & 0.8500 & 0.8494 \\
\hline API gravity @ $60^{\circ} \mathrm{F}$ & 27.9 & 33.35 & 34.97 & 35.49 \\
\hline RI @ 20 & 1.4860 & 1.4775 & 1.4730 & 1.4680 \\
\hline Kinematic viscosity, cSt, @ $40^{\circ} \mathrm{C}$ & 5.11 & 4.74 & 3.27 & 2.48 \\
\hline Pour point, ${ }^{\circ} \mathrm{C}$ & +9 & 6 & 3 & 3 \\
\hline Flash point, ${ }^{\circ} \mathrm{C}$ & 87 & 80 & 58 & 44 \\
\hline Color & 8 & 1.5 & 1 & 1 \\
\hline \multicolumn{5}{|l|}{ Component analysis } \\
\hline Total saturates, wt. $\%$ & 63.88 & 76 & 78.5 & 83.2 \\
\hline Total aromatics, wt.\% & 34 & 24 & 21.5 & 16.8 \\
\hline Resin & 2.12 & - & - & - \\
\hline Hydrodearomatization (HDA), wt $\%$ & - & 29.41 & 36.76 & 50.58 \\
\hline
\end{tabular}


Effect of time

Table 5 represented the effect of time on the product quality of HVGO. Increasing the time from 2 to $4 \mathrm{hr}$, the hydrogenation function of the catalyst was increased due to the increase in the contact time between the reacting HVGO molecules and the acid hydrogenation sites of the catalyst.

As a result the HDS activity of the catalyst increased from (77.1 to 83.1\%) and the improvement of, color, total aromatics content, aniline points and diesel index were observed. This means that improvement in the quality of heavy vacuum gas oil by increasing time from 2 to $6 \mathrm{hr}$.

TABLE 5. Effect of reaction time on Hydrotreating of $\mathrm{HVGO}$ by $\mathrm{CoMoS} / \mathrm{CNT}$ at $\mathrm{P}=$ 40 bar, $\mathrm{T}=350{ }^{\circ} \mathrm{C}, \mathrm{C} / \mathrm{F}$ ratio $=1: 75$.

\begin{tabular}{|l|c|c|c|c|}
\hline \multirow{2}{*}{ Characteristics } & \multicolumn{4}{|c|}{ Time, h } \\
\cline { 2 - 5 } & Feed & $\mathbf{2}$ & $\mathbf{4}$ & $\mathbf{6}$ \\
\hline Total liquid yield, wt \% & 150 & 78 & 75.33 & 69.2 \\
\hline Total sulfur content, wt \% & 1.66 & 0.38 & 0.36 & 0.28 \\
\hline Sulfur reduction (HDS), \% & - & 77.1 & 78.3 & 83.1 \\
\hline Aniline point @ ${ }^{\circ} \mathrm{F}$ & 165.2 & 170.6 & 170.96 & 172.04 \\
\hline DI & 46.09 & 59.65 & 60.1 & 60.66 \\
\hline Density @ 15.56 ${ }^{\circ} \mathrm{C}, \mathrm{g} / \mathrm{ml}$ & 0.8867 & 0.8492 & 0.8489 & 0.8482 \\
\hline Specific gravity & 0.8876 & 0.8500 & 0.8497 & 0.8490 \\
\hline API gravity @ 60 ${ }^{\circ} \mathrm{F}$ & 27.9 & 34.97 & 35.16 & 35.26 \\
\hline RI @ 20 & 1.4860 & 1.4730 & 1.4695 & 1.4675 \\
\hline Kinematic viscosity, cSt, @ 40 ${ }^{\circ} \mathrm{C}$ & 5.11 & 3.27 & 2.97 & 2.43 \\
\hline Pour point, ${ }^{\circ} \mathrm{C}$ & +9 & 3 & 3 & 3 \\
\hline Flash point, ${ }^{\circ} \mathrm{C}$ & 87 & 58 & 55 & 45 \\
\hline Color & 8 & 1 & 1 & 1 \\
\hline Component analysis & 63.88 & 78.5 & 82 & 84 \\
\hline Total saturates, wt.\% & 34 & 21.5 & 18 & 16 \\
\hline Total aromatics, wt.\% & 2.12 & - & - & - \\
\hline Resin & - & 36.76 & 47.05 & 52.94 \\
\hline Hydrodearomatization (HDA), wt\% & & & & \\
\hline & & & & \\
\hline
\end{tabular}

Egypt. J. Chem. 59, No. 3 (2016) 


\section{Effect of catalyst/oil ratio}

The amount of catalyst was also very important for hydrotreating process. Figure 5 Showed the effect of weight of catalyst on the HDS of heavy gas oil, when the amount of catalyst was $2 \mathrm{~g}$ the HDS reached (77.1\%) due to the absence of enough active sites for the reaction due to the least amount of catalyst. With farther increase the weight of catalyst to (4.54) and (15) g the HDS increased to (82.7) and (94.8), respectively, due to the increased in the amount of catalyst and hence the increase in the number of acid sites available.

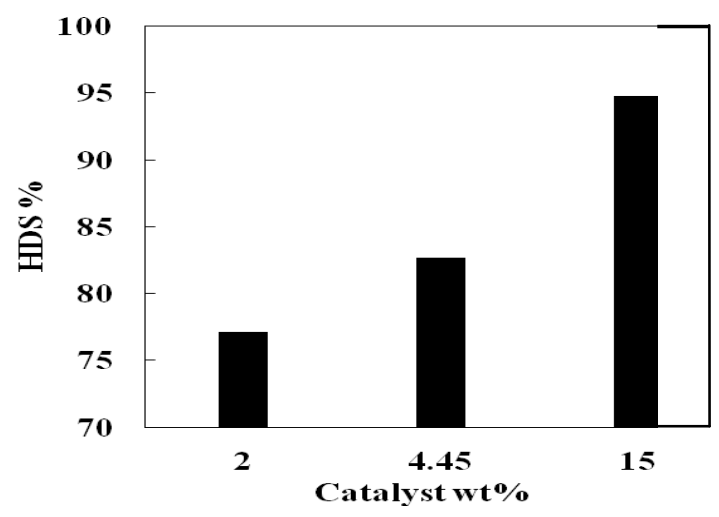

Fig. 5. Effect of catalyst/oil ratio (catalyst, wt) of CoMoS/CNT on HVGO at pressure: $40 \mathrm{bar}$, temperature: $350^{\circ} \mathrm{C}$, time: $2 \mathrm{hr}$.

\section{Conclusion}

The CoMoS/CNT hydrotreating catalyst was prepared by impregnation method. The TEM analysis of purified CNTs proved their morphological and structural features. Additionally, TEM indicated a good dispersion of Mo species and uniform Co particles deposition over the CNTs surface. The CNTs crystallinty and graphitic nature was determined by XRD and Raman Spectroscopy.

The catalyst, with $12 \mathrm{wt} \%$ Mo loading and $0.7 \mathrm{Co} / \mathrm{Mo}$ atomic ratios supported on CNT, exhibited an excellent catalytic performance towards hydrotreating process under the experimental conditions. Consequently, the desired promoted $\mathrm{Co}-\mathrm{Mo}-\mathrm{S}$ phase formation upon sulfidation process was confirmed. Also, from the high catalytic activity, it can be claimed that almost $90 \%$ of the sulfur compounds adsorb on CoMoS/CNT are in an endon manner. The high catalytic performance of CoMoS/CNT can be achieved at low operating condition of $350{ }^{\circ} \mathrm{C}, 40$ bar and catalyst/ratio of $1: 10$ for $2 \mathrm{hr}$. A fairly high HDS\% of $77.1 \%$ can be achieved over a low catalyst to oil ratio of 1:75. 


\section{Reference}

1. Topsee, H. and Clausen, B.S., Importance of Co-Mo-S type structures in hydrodesulfurization. Cat. Rev. - Sci. Eng. 26, 395-420 (1984).

2. Prins, R., De Beer, V.H.J. and Somorjai G.A., Structure and function of the catalyst and the promoter in Co-Mo hydrodesulfurization catalysts. Cat. Rev. - Sci. Eng., 31, 1-41 (1989).

3. Medici, L. and Prins, R., The influence of chelating ligands on the sulfidation of $\mathrm{Ni}$ and $\mathrm{Mo}$ in $\mathrm{NiMo} / \mathrm{SiO}_{2}$ hydrotreating catalysts. J. Catal. 163, 38-49 (1996).

4. Shimizu, T., Hiroshima, K., Honma, T., Mochizuki, T. and Yamada, M., Highly active hydrotreatment catalysts prepared with chelating agents. Catal. Today, 45, 2716 (1998).

5. Van Looij, F., Van der Laan, P., Stork, W.H.J., DiCamillo, D.J., and Swain, J., Key parameters in deep hydrodesulfurization of diesel fuel. Appl. Catal., A: General, 170, 1-12 (1998).

6. Shimada, H., Sato, T., Yoshimura, Y., Hiraishi, J. and Nishijima, A., Support effect on the catalytic activity and properties of sulfided molybdenum catalysts. J. Catal. 110, 275-84 (1988).

7. Vishwakarma, S.K., Sonochemical and impregnated Co- $\mathrm{W} / \gamma-\mathrm{Al}_{2} \mathrm{O}_{3}$ catalysts: Performances and kinetic studies on hydrotreatment of light gas oil. University of Saskatchewan Saskatoon (2007).

8. Topsee, H. and Clausen, B.S., Active sites and support effects in hydrodesulfurization catalysts. Appl. Catal. 25, 273-93 (1986).

9. Eswaramoorthi, I., Sundaramurthy, V., Das, N., Dalai, A.K. and Adjaye, J., Application of multi-walled carbon nanotubes as efficient support to NiMo hydrotreating catalyst. Appl. Catal., A: General, 339, 187-95 (2008).

10. Sigurdson, S., Sundaramurthy, V., Dalai, A.K. and Adjaye, J., Effect of anodic alumina pore diameter variation on template-initiated synthesis of carbon nanotube catalyst supports. J. Mol. Catal. A: Chem. 306, 23-32 (2009).

11. Dhar, G.M., Srinivas, B.N., Rana, M.S., Kumar, M. and Maity, S.K., Mixed oxide supported hydrodesulfurization catalysts-a review. Catal.Today, 86, 45-60 (2003).

12. Wang, A., Wang, Y., Kabe, T., Chen, Y., Ishihara, A. and Qian, W. Hydrodesulfurization of dibenzothiophene over siliceous MCM-41-supported catalysts: I. sulfided Co-Mo catalysts. J. Catal. 199, 19-29 (2001).

13. Maity, S.K., Rana, M.S., Bej, S.K., Ancheyta-Juarez, J., Dhar, G.M. and Rao, T.S.R.P. Studies on physico-chemical characterization and catalysis on high surface area titania supported molybdenum hydrotreating catalysts. Appl. Catal., A: General, 205, 215-25 (2001).

Egypt. J. Chem. 59, No. 3 (2016) 
14. Vradman, L., Landau, M.V., Herskowitz, M., Ezersky, V., Talianker, M. and Nikitenko, S. et al., High loading of short WS 2 slabs inside SBA-15: promotion with nickel and performance in hydrodesulfurization and hydrogenation. J. Catal. 213, 163-75 (2003).

15. Pour, A.N., Rashidi, A.M., Jozani, K.J., Mohajeri, A. and Khorami, P., Support effects on the chemical property and catalytic activity of Co-Mo HDS catalyst in sulfur recovery J. Nat.Gas Chem. 19, 91-5 (2010).

16. Serp, P., Corrias, M. and Kalck, P., Carbon nanotubes and nanofibers in catalysis. Appl. Catal., A: General, 253, 337-58 (2003).

17. van Steen, E. and Prinsloo, F.F., Comparison of preparation methods for carbon nanotubes supported iron Fischer-Tropsch catalysts. Catal. Today, 71, 327-34 (2002).

18. Auer, E., Freund, A., Pietsch, J. and Tacke, T., Carbons as supports for industrial precious metal catalysts. Appl. Catal., A: General, 173, 259-71 (1998).

19. Shang, H.Y., Liu, C.G., Xu, Y.Q., Zhao, H.J. and Song, H.H., Effect of the surface modification of multi-walled carbon nanotubes (MWCNTs) on hydrodesulfurization activity of Co-Mo/MWCNTs catalysts. Carbon Mater, 19, 131-6 (2004).

20. Kyotani, T., Nakazaki, S., Xu, W.H. and Tomita, A., Chemical modification of the inner walls of carbon nanotubes by $\mathrm{HNO}_{3}$ oxidation. Carbon, 39, $782-5$ (2001).

21. Dong, K., Zhang, S., Wang, D. and Yao, X., Hydrogen bonds in imidazolium ionic liquids. J. Phys .Chem. A, 110, 9775-82 (2006).

22. Shang, H., Liu, C., Xu, Y., Qiu, J. and Wei, F., States of carbon nanotube supported Mo-based HDS catalysts. Fuel Process Technol. 88, 117-23 (2007).

23. Awadallah, A.E., Aboul-Enein, A.A., El-Desouki, D.S. and Aboul-Gheit, A.K., Catalytic thermal decomposition of methane to $\mathrm{CO}$ x-free hydrogen and carbon nanotubes over $\mathrm{MgO}$ supported bimetallic group VIII catalysts. Appl. Surf. Sci. 296, 100-7 (2014).

24. Sundaramurthy, V., Dalai, A.K. and Adjaye., J., Effect of EDTA on hydrotreating activity of $\mathrm{CoMo} / \gamma-\mathrm{Al}_{2} \mathrm{O}_{3}$ catalyst. Catal. Lett. 102, 299-306 (2005).

25. Hogg, J.C., Chu, F., Utokaparch, S., Woods, R., Elliott, W.M. and Buzatu, L. et al., The nature of small-airway obstruction in chronic obstructive pulmonary disease. Engl. J. Med. 350, 2645-53 (2004).

26. Shigapov, A.N., Graham, G.W., McCabe, R.W., Peck, M.P. and Plummer, H.K., The preparation of high-surface-area cordierite monolith by acid treatment. Appl. Catal., A: General, 182, 137-46 (1999).

27. Tan, Z.l., Xiao, H.N., Zhang, R.D., Zhang, Z.S. and Kaliaguine, S., Potential to use mesoporous carbon as catalyst support for hydrodesulfurization. New Carbon Mater, 24, 333-43 (2009). 
28. Zhang, Y., Zhang, H.B., Lin, G.D., Chen, P., Yuan, Y.Z. and Tsai, K.R., Preparation, characterization and catalytic hydroformylation properties of carbon nanotubes-supported Rh-phosphine catalyst. Appl. Catal., A: General, 87, 213-24 (1999).

29. Dujardin, E., Ebbesen, T.W., Hiura, H. and Tanigaki, K., Capillarity and wetting of carbon nanotubes. Science, 265, 1850-2 (1994).

30. Dandekar, A., Baker, R.T.K. and Vannice, M.A., Characterization of activated carbon, graphitized carbon fibers and synthetic diamond powder using TPD and DRIFTS. Carbon, 36, 1821-31 (1998).

31. Karimi, A., Nasernejad, B. and Rashidi, A.M., Synthesis and characterization of multiwall carbon nanotubes/alumina nanohybrid-supported cobalt catalyst in FischerTropsch synthesis. J. Energy Chem. 22, 582-90 (2013).

32. Trépanier, M., Tavasoli, A., Dalai, A.K. and Abatzoglou, N., Fischer-Tropsch synthesis over carbon nanotubes supported cobalt catalysts in a fixed bed reactor: Influence of acid treatment. Fuel Process.Technol. 90, 367-74 (2009).

33. Karimi, A., Nasernejad, B., Rashidi, A.M., Tavasoli, A. and Pourkhalil, M., Functional group effect on carbon nanotube (CNT)-supported cobalt catalysts in Fischer-Tropsch synthesis activity, selectivity and stability. Fuel, 117, 1045-51 (2014).

34. Abbaslou, R.M.M., Tavassolim, A., Soltanm, J., and Dalai, A. K., Iron catalysts supported on carbon nanotubes for Fischer-Tropsch synthesis: Effect of catalytic site position. Appl. Catal., A: General, 367, 47-52 (2009).

35. Dresselhaus, M.S., Dresselhaus, G., Jorio, A., Souza Filho, A.G. and Saito, R., Raman spectroscopy on isolated single wall carbon nanotubes. Carbon, 40, 2043-61 (2002).

36. Li, Q., Yan, H., Zhang, J. and Liu, Z., Effect of hydrocarbons precursors on the formation of carbon nanotubes in chemical vapor deposition. Carbon, 42, 829-35 (2004).

37. Kohler, S.D., Ekerdt, J.G., Kim, D.S. and Wachs, I.E., Relationship between structure and point of zero surface charge for molybdenum and tungsten oxides supported on alumina. Catal. Lett. 16, 231-9 (1992).

38. Jeziorowski, H., Knozinger, H., Grange, P.and Gajardo, P., Raman spectra of cobalt molybdenum oxide supported on silica. J. Phys. Chem. 84, 1825-9 (1980).

39. Gary, J.H., Handwerk, G.E. and Kaiser, M.J., Petroleum Refining: Technology and Economics: CRC press, (2007).

40. Bartholomew, C.H., Catalyst Deactivation in Hydrotreating of Residua: A Review: Marcel Dekker: New York, (1994).

(Received 3/2/2016;

accepted 2/3/2016)

Egypt. J. Chem. 59, No. 3 (2016) 


\section{المعائجة المائية لزيوت الثفط المصرية الثقيلة في وجود حافز كوبالت ـ مولبذنيوم في أنبوبة من | الثنانوكريون}

وائل أحمد ، هدى أحمد ، هدى الثيثتاوي ، نادية محدث و أسماء زهرات معهد بحوث النتزرول وثقسم انكيمياء - كلية التزربية و انعلوم (بنات)- جامعة عين شمس - القاهزة - مصر.

قدم هذا البحث طريقة جديدة لنتقية العسو ائل مثل الزٔيوت النترولية المصرية انثقيلة وانتى تستخدم فى أجهزة

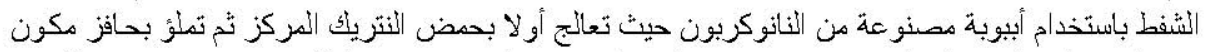

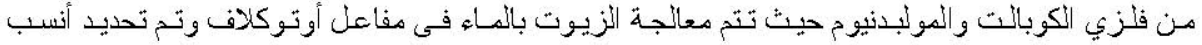

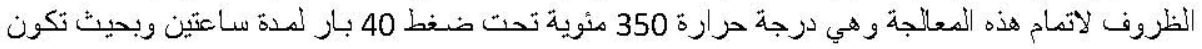
نسبة انحافز النى الزيت المعالج هي 1 : 75. 